Centre for Evidence Based Medicine, Nuffield Department of Primary Care Health Sciences, University of Oxford, Oxford

jeffrey.aronson@phc.ox.ac.uk Cite this as: BMJ 2021;375:n2712 http://dx.doi.org/10.1136/bmj.n2712 Published: 5 November 2021

\section{When I use a word .... The efficiency paradox}

\begin{abstract}
The efficiency paradox in healthcare arises from the mistaken belief that maximizing the use of resources necessarily improves overall efficiency. A recent study in patients with arthropathies or lupus suggests that attempting to improve efficiency by using telemedicine may in fact reduce the efficient delivery of healthcare for some patients, and even for some doctors.
\end{abstract}

\section{Jeffrey K Aronson}

I recently bumped into Pat, an erstwhile patient of mine, who has since moved out of the area. Pat gave me a telling off. "This health service of yours, doctor, is in a mess." I ignored the assertion that I own the NHS and that, by implication, I'm therefore to blame.

"Look," said Pat, "I understand that there aren't enough of you. And that you're all under enormous pressure. And I sympathize. Wholeheartedly. Believe me. After all, I was out there applauding last year with the rest of them. But everything you're doing seems to me designed to help you and not me.

“Take this hip of mine," Pat went on, pointing to it. "It's pretty painful. Age, no doubt. Wear and tear, I suppose. But I wanted a proper opinion. So I phoned the practice and a receptionist quizzed me about why I wanted to see the doctor. She said I could have a video consultation in two weeks. Not what I wanted really, but better than nothing. The doctor quizzed me and said it was probably wear and tear. Although he used a more fancy name. Anyway, he said he'd give me a referral-didn't say to whom. That sounded promising, and four weeks later I got an appointment to see a physio. She was very pleasant. Prescribed a weekly workout at the clinic and some exercises to do at home. Much like what I do at the gym every day. Now, another three months later, nothing's changed, and I'm still wondering about other options.

"Then a friend told me the physio could have referred me to a surgeon, who might have helped. She hadn't mentioned that. My fault for not asking, I suppose. Not that I want a new hip, you understand, which is probably what they'd want to give me, though I'd probably have to wait an age for that too. But I'd think about it, and maybe there's a simpler alternative. At least they might have told me what the options were and the likely outlook.

"So, what I'm saying, if you get my drift, is that in making life easier for himself, the GP's made it more complicated for me. It's the efficiency paradox." Pat obviously saw the quizzical look on my face. "Read it up, Doc. Read it up."

I wanted to find convincing arguments that it was more complicated than Pat was suggesting, but I knew that, whatever I said, the response would be dismissive. And anyway, I hadn't heard of the efficiency paradox. So I did as I'd been told-I went and read it up.

None of the various definitions of a paradox in the Oxford English Dictionary (OED) fits the usage it gets in the term "efficiency paradox." The definitions are arranged in six groups, with the relevant current meanings in the second set, which includes three definitions:

An apparently absurd or self-contradictory statement or proposition, or a strongly counter-intuitive one, which investigation, analysis, or explanation may nevertheless prove to be well founded or true.

[A proposition or statement that is (taken to be) actually self-contradictory, absurd, or intrinsically unreasonable.

CAn argument, based on (apparently) acceptable premises and using (apparently) valid reasoning, which leads to a conclusion that is against sense, logically unacceptable, or self-contradictory; the conclusion of such an argument.

None of these, for me, captures the essence of the efficiency paradox.

The word paradox comes from the Greek adjective $\pi \alpha \rho \alpha \dot{\delta} \delta \xi \circ$, , which literally means contrary to expectation. It is therefore disappointing that none of the definitions on offer quite grasps the frustrated expectation that the efficiency paradox implies. However, another word more closely captures the meaning, antinomy, an etymological hybrid, from the Latin anti, against, and the Greek vó $\mu$ os, usage. Immanuel Kant introduced it in Kritik der reinen Vernunft (Critique of Pure Reason, 1781) to describe the possibility of deriving two entirely logical but opposite conclusions, thesis and antithesis, about some property of the world; for example, the necessity yet impossibility of free will. Following Kant, the OED defines "antinomy" as both a count noun, "a contradiction between conclusions which seem equally logical, reasonable, or necessary,” and, more succinctly, a non-count noun, 1 "intellectual contradictoriness.” That's more like it.

The type of antinomy that the efficiency paradox embodies is an idea or state of affairs that leads to an outcome that is opposite to the expected outcome. It has been entertainingly discussed in a book titled This is Lean, by Niklas Modig and Pär Åhlström. ${ }^{2}$ The arguments relate to the world of management (I know, I know), but the book includes accounts from the world of healthcare. Briefly, because of the mistaken belief that maximizing the use of resources improves efficiency, Pat actually experienced inefficiency.

Evidence of this phenomenon comes this week from a mixed-methods study, published in Rheumatology, of the effects of telemedicine as used by 111 clinicians 
and experienced by 1340 patients with inflammatory arthropathies or lupus (https://pubmed.ncbi.nlm.nih.gov/34698822/). The authors reported that concerns about telemedicine included: reduced assessment accuracy; impaired medical relationships; increased inequalities for vulnerable and/or disadvantaged patients; and limited emergency access from barriers to patient-initiated contact, including gate-keeping administrators and non-responsiveness. This is reminiscent of another well known phenomenon, the inverse care law, ${ }^{3}$ by which those most in need of care are the least likely to get it. ${ }^{3}$ By and large, the patients were less impressed with the telemedicine system than the clinicians. For example, $20 \%$ of the patients thought that it was less convenient than face-to-face consultation, compared with only $7 \%$ of the clinicians; and $54 \%$ of the patients thought that it gave them less time, compared with $27 \%$ of the clinicians. Furthermore, the clinicians overestimated the convenience that the system afforded their patients. And, perhaps contrary to expectation, remote consultations did not always actually save clinicians' time and sometimes involved more administration. The report of this study is dense with data and repays close reading.

Some clinicians may find these results unpalatable and refuse to accept them as relevant to their own practice or patients. The correspondence will be interesting to read. But given the current problems in the NHS, it is hard to see how the efficiency paradox can be resolved.

And I still don't know what I should have said to Pat.

Note: The dialogue of Pat is based on an amalgam of conversations that the author has had.

Competing interests: none declared.

Aronson J. Words that count. BMJ2007;334:1104doi: 10.1136/bmj.39196.640637.BE.

Modig N, Åhlström P. This is Lean: Resolving the Efficiency Paradox. Rheologica Publishing, 2013.

Tudor-Hart J. The inverse care law. Lancet 1971;1:405-12.

doi: 10.1016/S0140-6736(71)92410-X pmid: 4100731 